\title{
O CUSTO DO FINANCIAMENTO DAS VENDAS A PRESTACOES NO BRASIL
}

POLIA LERNER HAMBURGER JORGE WILSON SIMIERA JACOB

"A disponibilidade de vendas a prestação tem ajudado a compensar, de certa forma, as desigualdades de poder aquisitivo entre os consumidores. Tornou mais fácil a grupos de menor renda comprar bens de alto valor unitário que, de outra forma, teriam sido comprados principalmente por grupos de renda mais alta." (Do FEDERAL RESERVE BOARD: Consumer Instâlment Credit.)

As vendas a prestações tendem a representar, cada vez mais, apreciável percentagem do volume total de vendas no varejo em nosso País. Levantamento de dados feito no primeiro semestre de 1965 por alunos do Seminário de Administração Varejista do $4 .^{\circ}$ ano do Curso de Graduação da Escola de Administração de Emprêsas de São Paulo, da Fundação Getúlio Vargas, revela que em várias lojas de departamentos da capital paulista a proporção das vendas a prazo em relação ao volume total de vendas varia de 50 a $80 \%$, e que em Belo Horizonte essa proporção chega, pelo menos num caso, a 99\%. O Censo dos Lojistas da Guanabara, realizado em 1964 pela DATAMEC ${ }^{1}$, assinala as seguintes percentagens das vendas a crédito sôbre a venda total: mínima de $9,80 \%$, máxima de $94,40 \%$ e média de $68,70 \%$.

Pólia Lerner Hamburger - Professôra-Adjunta e Chefe do Departamento de Mercadologia da Escola de Administração de Emprêsas de São Paulo, da Fundação Getúlio Vargas.

joRge WiLsonSImiera JACOB - Diretor da cadeia de lojas "Arapuã" de Lins (SP). Participante do XXVI. ${ }^{\circ}$ Curso Intensive de Administradores da EAESP.

1) DATAMEC - Organização e Serviços Mecanizados S.A. (emprêsa do grupo "Ducal") . 
As vendas a prestações são apenas uma das várias formas de crédito ao consumidor, mas são a mais comum. As demais formas de crédito ao consumidor - empréstimos para aquisição de bens de consumo, vendas em conta corrente e oferta de serviços a crédito - não ocorrem nem com a freqüência nem com o montante das vendas a prestações.

A que se deve o desenvolvimento cada vez maior das vendas a prestações? A análise das suas vantagens para o consumidor de um lado, e para o comerciante, de outro, traz resposta a essa pergunta.

Para o consumidor o crediário traz um aumento do poder aquisitivo, porquanto proporciona maior possibilidade de aquisição imediata de grande variedade de bens (inclusive bens duráveis, de alto custo) e conseqüente melhoria do padrão de vida; além disso, pelo compromisso que implica de saldar prestações, força a poupança.

Para o comerciante as vendas a prestações aumentam o volume de vendas, não só pela maior procura de bens, como pela manutenção de lista atualizada de endereços de fregueses e pelo auxílio do departamento de crédito na obtenção de novas vendas.

De maneira geral, pode-se dizer que para a economia considerada como um todo, desde que mantidas dentro de certos limites, as vendas a prestações são benéficas, pois criam um mercado em massa para bens de alto valor unitário e proporcionam a elevação to padrão de vida da comunidade. Isso não significa que não tenham suas desvantagens. Para o consumidor as vendas a prestações significam preços mais elevados dos produtos pela taxa de juros que lhes acrescentam; podem representar, também, compras maiores do que o poder aquisitivo real justificaria, com conseqüente descontrôle do orçamento doméstico. Para o comerciante acarretam aumento dos trabalhos e custos operacionais, pela necessidade de manutenção do 
crediário e pelo aumento dos riscos de perdas de contas maior financiamento.

Essa necessidade tem levado os varejistas a usarem seus próprios recursos ou a procurarem recursos externos de financiamento, principalmente o crédito mercantil, isto é, o crédito fornecido por fabricantes ou atacadistas, e o financiamento de companhias de investimentos. $O$ crédito bancário, os concursos, brindes, carnês e outras formas de vendas com pagamento antecipado, bem como o lançamento de debêntures a curto prazo, são recursos de que só esporàdicamente se valem os varejistas para êsse fim.

O crédito mercantil ainda é a principal fonte de crédito do varejista. O prazo médio concedido por fornecedores, de acôrdo com o Censo dos Lojistas da Guanabara, de 1964, gira em tôrno de 100 dias. Os bancos não representam fonte expressiva de crédito para o varejista, não só pelo baixo valor dos títulos, como pela garantia unilateral na operação (geralmente, o consumidor só conta com o crédito pessoal) e pelo prazo limitado a 90 e 120 dias. Para o varejista a perda de contato com o cliente e a reação desfavorável da freguesia pela cobrança bancária somam-se aos fatôres citados anteriormente. Nas grandes capitais as companhias de financiamento operam razoàvelmente com o varejo, pois evitam alguns dos fatôres negativos apresentados pelos bancos. Os carnês e o lançamento de debêntures são as formas menos usadas pelos varejistas.

Essa variedade de recursos está a indicar, segundo entendemos, que as emprêsas estão sentindo a crescente necessidade de procurar fontes externas para o financiamento de suas vendas a prestações.

POLITICA DE CREDITO E CUSTO DE FINANCIAMENTO

O custo de financiameto não inclui apenas o custo do dinheiro no mercaldo: é formado também pelo custo de operação do crediário (concessão, administração, cobrança, 
atrasos, riscos, perdas), custo que não existe quando as vendas são realizadas à vista.

Ao estabelecer sua política de crédito, a emprêsa varejista deve considerar êsses dois custos, porque o uso descomedido dessa importante arma de mercadização, que é o crédito, dá origem, necessàriamente, ao descontrôle financeiro.

Quais são os planos mais comuns na política de vendas a crédito?

- O segundo plano apresenta um preço à vista, sem qualpreço calculado para certo prazo, sem mais acréscimos, com desconto para venda a vista e acréscimo suave para prazos mais longos do que o oferecido pelo plano básico. Exemplo: o preço de tabela é de Cr $\$ 100.000$, sem acréscimo, para o prazo de dez meses; para compra a vista dá-se o desconto de $10 \%$ (que representa o juro disfarçado); para prazos maiores haverá o acréscimo "declarado" ao redor de $2 \%$ por prestação. Êsse plano é, em geral, bem aceito pelo cliente, que não sente a realidade do custo do dinheiro.

- O segundo plano apresenta um preço à vista, sem qualquer desconto, com acréscimo sôbre o saldo devido, qualquer que seja o prazo concedido. As taxas "reais" nesse caso oscilam entre 3,2 e 4\% por prestação e representam realmente o que a loja deseja ou precisa cobrar pelo financiamento (no exemplo tado, Cr\$100.000 à vista; para o prazo de 10 meses seriam acrescidos $32 \%$ sôbre - saldo a ser financiado, deduzida a entrada). Quanto signifique realmente essa taxa depende do prazo, conforme se pode ver no Quadro 1. Nesse quadro demonstramos que uma taxa de juros constantes para diferentes planos de pagamentos significa, na realidade, uma taxa decrescente sôbre o total a pagar, à medida que o prazo aumente. Portanto, para manter constante em planos com duração heterogênea a taxa real sôbre o total a pagar, as taxas declaradas terão de ser crescentes, à medida que o prazo aumente. 


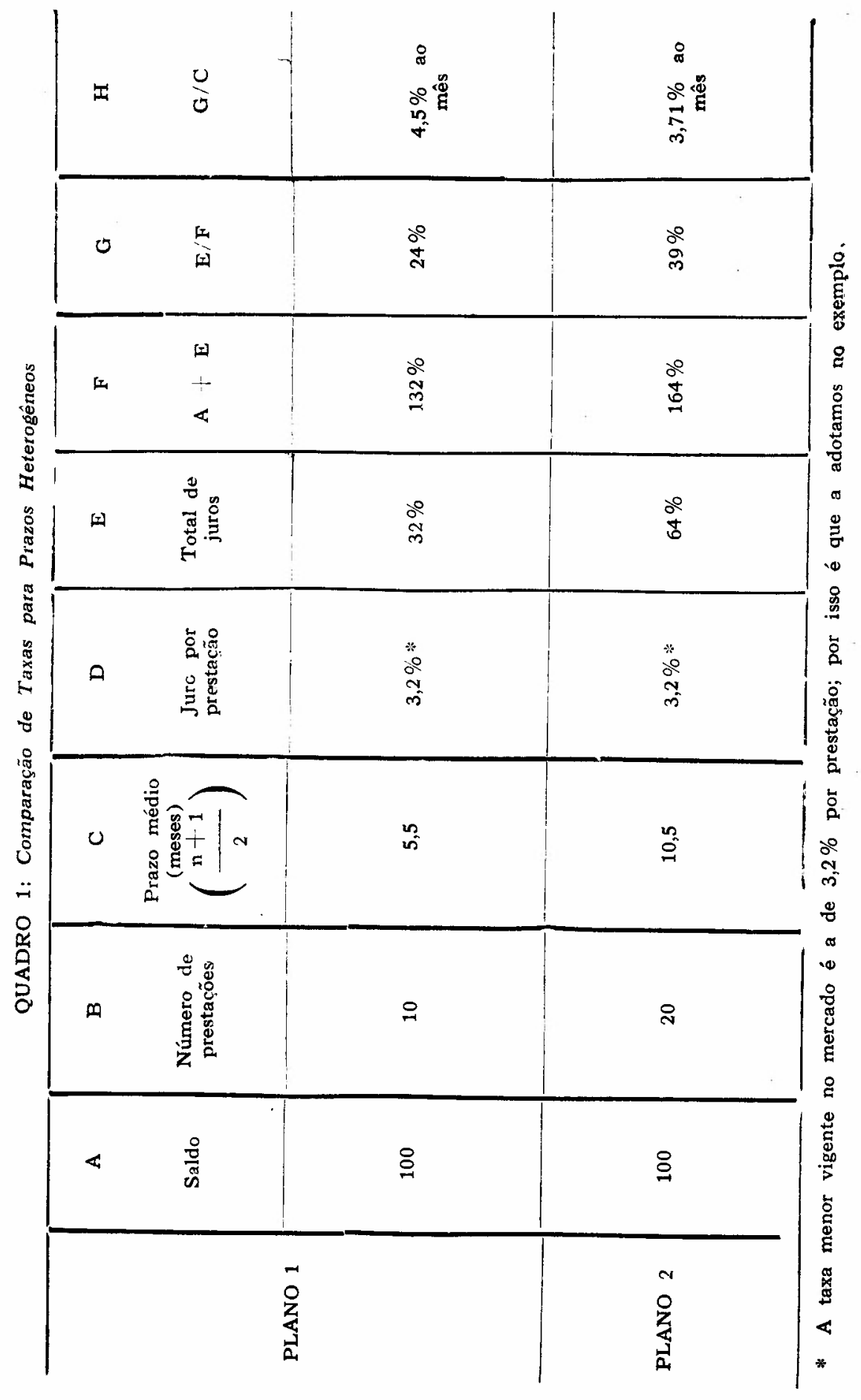


Note-se que falamos em juros "por prestação", não "por mês". A diferença é que o juro por mês se refere ao prazo médio, enquanto que o juro por prestação se refere ao acréscimo a cada parcela, a cada pagamento. Por exemplo: 10 prestações pagas mensalmente correspondem a um prazo médio de 5,5 meses (prazo médio $=\frac{\mathrm{n}+1}{2}$ onde $n$ é o número total de prestações). Essa diferença explica a diversidade entre a taxa declarada e a real. A taxa é declarada por prestação, mas na realidade se aplica a um prazo médio porque o saldo não é pago todo de uma vez, no fim do período, mas em parcelas mensais. A taxa real se obtém pela seguinte fórmula: $T=\frac{2 \mathrm{n} t}{\mathrm{n}+1}$, onde $T$ é a taxa real, $n$ o número de prestações e $t$ a taxa declarada. ${ }^{2}$ Para uma visão mais clara do problema deve ser introduzida, mesmo nessa fórmula de taxa real, uma correção que considere os diferentes prazos, como se vê no exemplo dado no Quadro 1.

CUSTO DO DINHEIRO E CUSTO TOTAL DA VENDA A CRÉDITO

Para o cálculo do custo do dinheiro podemos tomar por base o custo nas companhias financiadoras, que geralmente operam nas seguintes condições:

- prazo: de 7 a 12 meses;

- taxa de juros: mais ou menos $38,5 \%$ ao ano, sôbre o total que se passa a dever; ${ }^{3}$

2) N. R. - O exame da dedução e dcs valôres que compõem a fórmula é feito no artigo "Análise de Investimentos e Inflação", de autoria de Claude MACHLINe, neste mesmo número da Revista de Administração de Emprêsas.

3) Convém distinguir entre juro sôbre o preço-base e juro sôbre o total que se passa a dever (ou, como se diz vulgarmente, entre "juro por dentro" e "juro por fora"). Supondo-se, por exemplo, um preço 100 e uma taxa total de juros 20 , temos que, expressa sôbre 100 , essa taxa significa $20 \%$; mas, expressa sôbre os 120 que se passa a dever, ela representa apenas $16,7 \%$. 
caução: para um desconto de $100 \%$ é necessária uma caução extra te $33 \%$. $^{4}$

Podemos demonstrar êsse custo por meio de um exemplo:

prazo: 10 meses (prazo médio, já que os prazos variam de 7 a 12 meses);

- taxa de juro: $32 \%$ (38,5\% é a taxa ao ano);

- caução: $33 \%$ (com essa caução o varejista precisa imobilizar $133 \%$ para receber por 10 meses um líquido de $68 \%$; portanto, apenas a metade do dinheiro é realizada).

Nas vendas a vista os custos a considerar são o custo da mercadoria, o das despesas operacionais e o do rateio do capital próprio, enquanto que, como já dissemos, o custo total da venda a crédito não é apenas o custo do dinheiro pelo prazo concedido: nêle devem ser incluídos, também, os custos das despesas de operações da loja (despesas gerais, como nas vendas à vista, mais as despesas de operação do crediário), dos riscos e perdas por devedores duvidosos, dos atrasos nos pagamentos e, ainda, do rateio da remuneração do capital próprio envolvido no financiamento. (Damos exemplo da composição dêsses custos no Quadro 2.)

Se nas vendas a prestações fôsse possível passar a terceiros o financiamento - o que é improvável - o custo total não incluiria o custo do rateio da remuneração do capital próprio. Como isso não é aconselhável, pois os bancos e as companhias financiadoras têm como critério vender o dinheiro a taxas superiores às que pagam, a participação do capital de giro próprio tende a onerar o cálculo.

O custo da remuneração do capital próprio pode ser igual ao custo do dinheiro no mercado, mas também pode diferir

4) De acôrdo com o Boletim Banas Informa de $28 / 6 / 1965$, as companhias de investimentos emprestavam a uma taxa que chegou em 1964 até a $60 \%$ ao ano. Atualmente, porém, essas taxas baixaram muito, não só em virtude de fatôres psicológicos, como pela menor solicitaçāo de financiamento, derivada da diminuição de faturamento. A mesma publicação assinala a taxa média de $36 \%$ em junho de 1965 . 


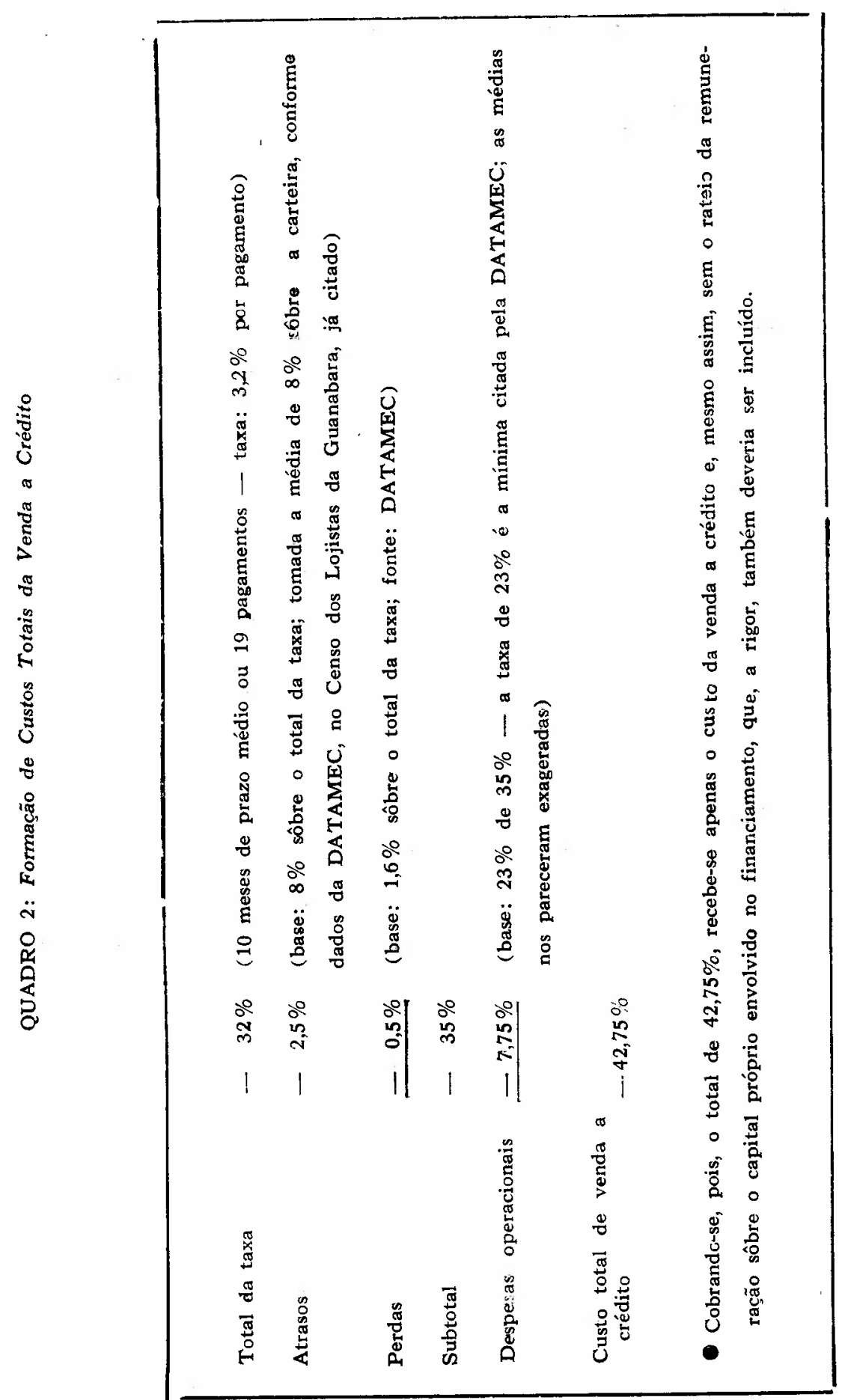


dêle. Se fôsse possível conseguir dinheiro "barato", o custo do capital próprio deveria ser maior do que o cobrado no mercado, para evitar descapitalização. Mas como obter dinheiro "barato"? A taxa de juros pode ser menor do que a taxa de inflação, por exemplo. No preço cobrado no mercado o único cuidado a tomar seria o de "revender" - capital por preço igual ou superior ao que se tivesse pago. A remuneração do capital próprio empregado em financiamento, porém, tem de ser equivalente à remuneração que se obteria pelo emprêgo dêsse mesmo capital nas operações de compra e venda.

No cálculo de custos o varejista deve, portanto, basear-se na remuneração que o capital de giro consegue nas operações normais da emprêsa. Sendo assim, êle deve calcular a participação do capital de giro próprio para rateá-lo sôbre o total financiado. Supondo-se, por exemplo, que no financiamento o lojista use $50 \%$ de capital próprio e $50 \%$ de capital de terceiros, êle deve calcular a remuneração dos $50 \%$ de capital próprio e rateá-los pelos $100 \%$ de financiamento concedido. ${ }^{5}$ Se êle conceder um total de financiamento de $\mathrm{Cr} \$ 100.000 .000$ num ano, dos quais Cr\$ 50.000.00 sejam próprios, e considerar adequada a remuneração de $30 \%$ por ano, êle terá de ratear Cr\$ 15.000.000 sôbre Cr\$100.000.000, o que dará cêrca de $1,5 \%$ em prazo médio. No cálculo de formação de custo o rateio seria, nesse caso, de $1,5 \%$.

\section{CONCLUSÃO}

O benefício das vendas a prestações para o consumidor, traduzido na possibilidade que estas lhe dão de atingir melhor padrão de vida pela compra de bens que pode utilizar antes de pagar, contribui certamente para o desenvolvimento da economia, pela criação de um mercado em massa que doutra forma não existiria, dada a limitação

5) Vale a pena lembrar a incidência do impôsto de renda sôbre êsse lucro fictício (no caso de acréscimos sôbre o capital próprio) representado pela taxa que se cobra para compensar a inflação. 
do poder aquisitivo de boa parte da população em nosso País.

$\mathrm{Na}$ medida em que o financiamento do varejista ao consumidor se destine à compra de bens duráveis e se realize a taxas inferiores à própria inflação - tais como as citadas neste artigo - , êle deve merecer todo o apoio pelas vantagens que proporciona ao consumidor e à economia. Se alguém tivesse de opor-lhe qualquer restrição, seriam os depositantes e/ou os tomadores de lêtras, que entregam suas poupanças aos bancos e financiadoras, e que são os únicos prejudicados no processo.

Por outro lado, os exageros na concessão de crédito, no que se refere a prazos e tipos de mercadorias vendidas (tais como bens de baixo valor unitário ou vida útil muito reduzida), assim como os abusos nas taxas cobradas nas vendas a prestações, certamente contribuem para a espiral inflacionária e, em última análise, prejudicam o consumidor.

A fórmula que aqui apresentamos de cálculo de composição dos custos do financiamento tem emprêgo geral apenas em suas linhas metodológicas, já que as taxas de juros, perdas, atrasos etc. devem ser adaptadas às condições próprias de cada emprêsa. Mas ela expressa a importância dêsses custos nas taxas cobradas, e o reconhecimento dessa importância é essencial para a determinação de uma política sadia de crédito em qualquer emprêsa varejista. 